\title{
XLIII. A short account of horizontal water-wheels
}

\section{W. Adamson Esq.}

To cite this article: W. Adamson Esq. (1817) XLIII. A short account of horizontal water-wheels, Philosophical Magazine Series 1, 50:234, 256-267, DOI: 10.1080/14786441708637774

To link to this article: http://dx.doi.org/10.1080/14786441708637774

曲 Published online: 27 Jul 2009.

Submit your article to this journal $\pi$

Џ Article views: 3

Q View related articles $₫$ 
or bioken in the lower part of them, which in my opinion arose from the unequal temperature and expansion in the exterior part of the boiler; this unequal temperature is causet by a quantity of water at all times under the flue, and consequently of lower temperature than the water above the flue; thereby cansing the upper part of the boiler to expand in a greater ratio than the under part of the boiler, which in my opinion caused the fracture: alluded to. This circumstance induced me to make use of wrought-iron boilers, as I have explained or described, in preierence to the other.

II a steam boat, what boiler would you most recommend to be used to insure safety to the persons on board; a wroughtiron or a cast-iron boiler ? - A wrought-iron boiler, properly constructed.

What safety-valves would you recommend to be placed to boilers on board stenm-boats, to insure the greatest satety, or to guard against the boiler's exploding; I mean as to number ?-I recommend at least two safety-valves; the nue to be placed under the lock and key of the proprietor of the vessel, so secured as not to be accessible to the engine-man; and one which the engine-man has the usual control of.

Have you any thing to recommend with regard to the particular construction of these safety-ralves, so as to insure thejr acting and constant operation ?-I would recommend the valve to be nearly flat or quite so, which I apprehend would he less liable to be fastened by the difference of temperature to which the valve and the seat might occasionally be subjected.

I suppose such a safety-valve would not be liable to be impeded by much friction?-As little friction as pertiaps can be.

You have not any thing particularly to suggest ?-No.

[To be continued.]

XLIII. A short Account of Horizontal Water-Wheels. By W. Adauson*, Esq.

$\mathrm{O}_{\mathrm{N}}$ perusing the works of mechanical writers, it appears, that many attempts have been made to construct horizoutal vaterwheels, on such a principle as would give them sufficient power for mechainical purposes; but that these attempts have often failed.

The principal kinds, of which we have any account, are :

1. Such as have their vanes or floats placed round the rim, hike those of a wind-mill, and which are made much broader shan the vein of water which is to strike them; the water is de-

* Communicated by the Author.

livered 
livered from a spout, which is so directed as that they may be struck in a direction perpendicular to their surface.

2 . Those which have their floats ranged round the rim of the wheel in planes inclined to the radius, but parallel to the axis.

3. Those which have the floats standing on a soal, or on the side of the rim, not pointing to the axis, but aside from it, so that they will admit of the spout being more conveniently placed.

4. The centrifugal wheel, commonly called Barker's mill.

This consists of an upright pipe or trunk, communicating with two horizontal arms, each having a hole near the end opening in opposite directions, and at right angles to the arms. The water is poured from a spout into the top of the trunk, and issues through the holes in the arms, with a velocity corresponding to their depth below the surface of the water, by which the arms are forced backwards, and a retrograde motion is given to the wheel.

5. In the year 1797 , a patent was taken out by Mr. Robert Beatson, for a method of constructing horizontal mills to go either by wind or water. The machine consists of four rectangular frames or wings, standing at right angles to each other on an upright shaft. The foats, which convist of some thin light substance, are fixed in the frames perpendicular to the horizon, and are so constructed, that when they face the wind or the current of water, they are shut, and flll up the whole space within the frame; but on the opposite side, when they return against the current, they are open, and permit the wind or water to pass between them.

This machine, as a water-mill, was intended to act in the current of a river, or by the ebbing and flowing of the tide.

These seem to be the principal kinds of horizontal wheels; and from the nature of the principles upon which they act, it is evident their powers must be very stmall.

It however appears that many are in use on the continent of Europe.

\section{An Explanation of the Neru Patent Horizomtal W ater-Wheel, and the Principles of its Action.}

A circular wall, in the form of a hollow cylinder, is built in a perpendirular position on a horizontal plane.

Through the side of the cylinder, at the bottom, several rectangular cuts or passages are made, the sides of which are perpendicular to the base, or bottom of the cylinder. and the length of each within, is about four times the widch. Fig. 1, Plate IV.

The passages or cuts are made quite rount the circumbence, and so near to each other, that the sections of their sides within, make an acute angle, and leave, between each two, a solid part

Vol. 50 No.23!. Oct. 1817 . 
in the form of a wedge, the edge of which is perpendicular to the base, so that a line drawn from the centre of the wheel to it, will form a right angle with that side of the cut which faces the centre. Fig. 1 .

Within the cylinder is placed the horizontal wheel, with floats, and a perpendicular axis or spindle, which turns on a point in the centre. Figs. 1 and 2.

The floats $\mathrm{FF}$ are rectangular planes, fixed round the edge of the wheel in planes passing through the centre, and perpendicular to the plane of the wheel. Their height is something greater than that of a cut, and their breadth rather more than its width: also their number may be about three times the number of cuts. But for the purpose of obtaining the most regular motion, the numbers of the cuts and floats ought to be prime to each other. Fig. 2.

The cylinder is surrounded by a reservoir of water, supported by a circular wall, which, in low falls, may be equal to its depth. Fig. 1.

The reservoir is filled, from the canal or river, by a stream flowing through a head or slit at the top of the outer wall, and at the bottom, the water flows through the cuts PP against the floats, and turns the wheel. Figs. 1 and 2.

The width of the cylinder within, $R R$, is continued downwards below the floats $\mathrm{FF}$, to a depth sufficient for permitting passages to be made under the reservoir, of sufficient capacity to take away the water as fast as it enters the inner cylinder. Fig, 2.

The passages at the bottom of the machine, showing the escape of the water, appear in the plate, for the want of room, to occupy only half the circumference, but ought to be continued quite round. Fig. 2.

In fig. 2 , where part of a perpendicular section of the machine is represented, the passage of the water appears to be only on one side, but the opposite side is supposed to pass through one of the solids which supports the reservoir and wall.

The wheel, to about half the radius, is open quite round the centre, for the purpose of permitting the free passage of the air; (this, in a large wheel, may be much more than half; the remainder is solid, quite round, and curved or dished on the under side, for the purpose of turning the water downwards, and preventing it from rising above the wheel, as it passes from the float, in a thin sheet to the centre, where it forms a head, which by its pressure facilitates its escape. Fig. 2 .

According to the manner in which the floats are fixed in the wheel, they ought, in the figure, to be invisible; but are made to appear, for the purpose of showing the nature of the action of the water against them. Fig. 1 . 
To find what depth the bottom passages ought to be, it will be only necessary to know the breadth and depth of the head through which the water flow's into the reservoir, as the same quantity must pass both places in the same time.

The perfection of this machine may be shown as follows :

1. The floats being open on all sides, except that opposite the centre, will prevent as much as possible, any reaction against the water coming in.

2. 'The space below the floats, and the passages from it, being always sufficient to take away the water as fast as it enters, will prevent any accumulation of tail water from impeding the floats.

3 . The velocity of the water being greater than that of the wheel, prevents any impediment by centrifugal force.

4. The force of the water through the cuts, arises from its perpendicular pressure from the surface to the centre of force, and therefore is the greatest possible.

5. The line of pressure against the floats, is as nearly perpendicular to their surface, and as near to the extremity of the radius, as it is possible to make it act against the floats of a wheel, and therefore the pressure against them cannot be greater.

6. The water acts against all the floats at the same time.

7. The whole of the water acts agaiust the floats.

$\mathrm{S}$. The water receives no check from the want of air.

9. No water-wheel can move with less friction.

Hence it must be evident, that these principles will give the greatest power that can possibly be obtained from the action of water upon a horizontal wheel :

But as a wheel acting on these principles has never before been tried, it was thought most advisable to put it to the test by experiment, previous to making it public. A very complete and perfect model (or rather a little mill) has therefore been made by Messrs. Bramah and Sons, at their manufactory in Pimlico, near London.

\section{The Model}

stands on a base of two feet diameter, and its height is 53 inches.

The outward cylinder, which supports the water in the reservoir, is of cast iron.

The inner cylinder, in which the wheel moves, is of wrought iron, and its lower end, through which the cuts or water passages are made, is of brass.

The depth of the reservoir is about 51 inches.

The number of euts or water passages is 24 , and their depth one inch.

The wheel and floats are of brass.

The diameter of the wheel is 12 inches, and the number of floats is 79 , a prime number. 
A mahogany wheel or pulley of equal diameter to the wheel is fixed on the top of the spindle, and above it one of about 6.8 inches diameter is fixed, for the purpose of making experiments.

The water escapes at the bottom quite round the machine.

\section{Experiments.}

With this model or mill, the following experiments were made.

When the reservoir was full to above four feet above the centre of pressure, or middle point in the euts, the wheel made nearly four revolutions in a second, and, as no weight was then suspended, this was its greatest velocity.

A cord was then fixed to the smaller wheel, and passed over a pullev, with a weight suspended, when twelve revolutions of the wheel made in

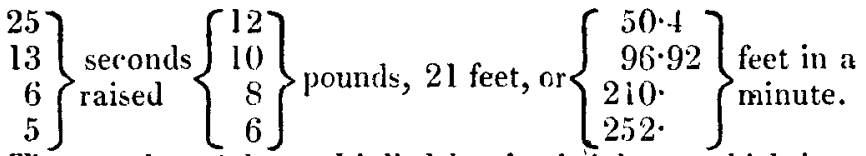

Then each weight multiplied by the height to which it was raised in a minute gives the momentum; therefore

$$
\left.\begin{array}{rl}
12 \times 50^{\circ} 4 & =60+\cdot 8 \\
10 \times 96.92 & =969.2 \\
8 \times 210^{\circ} & =1680 \cdot \\
6 \times 252^{\circ} & =1512 .
\end{array}\right\} \text { the nomentum. }
$$

Hence it appears, that the third experiment produced the greatest effect, and that the wheel then made twelve revolutions in six seconds, or two in one second, and therefore it moved with nearly half of its greatest velocity. Consequently, when the wheel moves with nearly half of its greatest velocity, it works to the greatest advantage, supposing the third experiment to be the maximum.

\section{Diameter or Sixe of the Wheel.}

'This wheel may be made of any diameter that may be required for making a given number of revolutions in a given time.

\section{Velocily.}

The wheel may move with any velocity whatever that can be obtained from the fall.

Mr. Banks, at page 105 of his Treatise on Mills, by taking a mean of the experiments made by six different authors, for the purpose of finding with what velocity water will issue from a fall of a given depth, gives $5.4 \times$ square root of the depth $=$ velocity of the water.

But according to these experiments, 6 comes much nearer than $5 \cdot 4$, and also agrees exactly with the experiments made by Banks himself; and as, in these experiments, it gives nearly the velocity 
velocity of the wheel, therefore $6 \times$ square root of the depth $=$ velocity of the wheel, and this may also, in practice, be taken for the velocity of the water without any material error, though its velocity will always be something greater than that of the wheel when moving without resistance.

On these principles a small wheel with a high fall will move with a velocity amazingly great. Thus, let the diameter of the wheel he one foot, and the height of the fall eighty-nine feet, then $6 \sqrt{89}=56 \cdot 60388$ feet, the velocity per second; and as the circumference of the wheel is $3 \cdot 1416$ feet; therefore

As $3 \cdot 1416: 1:: 5660388: 18$ revolutions per second. or $18 \times 60=1080$ revolutions in a minute.

\section{Power.}

In the specification, the power of the horizontal wheel was compared to that of the overshot, on a supposition that the force of is stream of water acting against a perpendicular plane near the orifice from which it flows, is nearly equal to the weight of the column which impels it, as Mr. Banks has proved by experiment.

But in making some experiments for the purpose of ascertaining the manner in which the water acts against the flonts of the horizontal wheel, it appeared,

That if a stream of water from a horizontal pipe, act against a perpendicular plane near the orifice $w$ ith any considerable force, it will spread quite round in a thin sheet parallel to the plane, and leave it on all sides in that direction ; and

That if the edge of the stream be brought a little beyond the edge of the plane, so that part of it may pass hy, it will form an angle with it; and that as the further side of the stream approaches the edge of the plane, the angle will increase until they coincide, when it will become a right angle.

Hence it is evident, that there is a reaction in this machine against the water coming in, which it is impossible to avoid, and that this is what reduces its power below that of the overshot wheel ; but that this reaction is very different from the centrifugal force.

$B \in f o r e$ we proceed to compute the power of the wheel, it is necessary to observe, that when the radius is one, the width of a cut is equal to the natural versed sine of the angle between two of them, taken at the centre, and therefore,

If the versed sine of the angle between two cuts be multiplied by any given radius, the product will be the width of a cut to that radius; and since all the cuts, in any cylinder, are cyual in width, as they are also in depth; therefore,

If the versed sine of the angle between two cuts be multiplied R 3 
by the radius, and then by the number and depth of the cuts, that is versed sine $x$ radius $x$ number $x$ depth, it gives the area of a rectangular section equal to the area of the perpendicular sections of all the cuts.

In the model the radius is six inches, the number of cuts twenty-four, and their depth one inch; the angle $15^{\circ}$, and its versed sine $\cdot 031074$; therefore

$.034074 \times 6 \times 24 \times \mathrm{I}=4.906056$ square inches, which, in consequence of the cuts having been made rather wider by dressing, is talien at five square inches or $\frac{5}{144}$ square feet, and the water being four feet deep, its velocity was $6 \sqrt{ } 4=12$ feet per second ;

Hence, $\frac{5 \times 12}{144}=\frac{5}{12}$ cubic feet of water issue in a second, or $\frac{5 \times 60}{12}=25$ cubic feet in a minute.

Therefore for the power, we have 25 cubic fcet, or $25 \times 62.5$ pounds of water descending through four feet in a minute; hence

The momentum of the power is $25 \times 62.5 \times 4=6250$.

Then to find the momentum of the effect, according to Mr. Smeaton's method;--when the wheel moved without water, a weight of ten onces gave it a velocity of two revolutions per second. Therefore accordiag to the third experiment, the weight raised was eight pounds ten ounces, or 8.625 pounds; consequently;

The inomentum of the effect was $8.625 \times 210=1811 \cdot 25$ and as $6250: 1811 \cdot 25:: 1: \cdot 2898$ the effect. But if the velocity of the water be found according to Mr. Banks's mean of the experiments of six difierent authors, it will be 10.8 feet per second, and the effect will be $\cdot 322$; and this makes the power of the horizontal wheel dsuble to that of the undershot, according to the second example in Mr. Smeaton's Table.

\section{Remark.}

Mr. Smeaton, at page 12 of his Treatise on Mills, gives an account of an experiment on the undershot wheel, where it ap pears that his head, or fall, of water was thirty inches, and that $264 \cdot 7$ pounds weight of water was expended, or descended through thirty inches in a minute; hence,

The momentum of the power was $264.7 \times 30=7941$, that 9.375 pounds weight of water was raised through 135 inches in a minute by the whecl; hence,

The momentum of the effect was $9.375 \times 135=1265.625$, therefore as $7941: 1265 \cdot 625:: 1: \cdot 1594$ the effect ${ }_{2}$ and $\cdot 1594 \times 2$ $=\cdot 3188=$ double the effect. 
But it appears that Mr. Smeaton has inserted $\cdot 32$ in his Table as the true effect in this case, on a supposition that the same effect may be obtained from half the power; and he therefore multiplies the weight of the water expended in a minute by 15 , or half the depth, instead of 30 , which was the depth through which the water, that turned the wheel, actually descended in a minute.

Had he made such a discovery as this, he ought to have given a demonstration, or a clear proof of its truth; for his argument about a virtual head, certainly gives no such proof: on the contrary, he says that he has obtained more than double of what is assigned by theory; and that this is very different from the opinions and calculations of authors of the first reputation.

The reason of making this remark is, that it is probable the power of the horizontal wheel will be compared with that of the undershot, according to Mr. Smeaton's Table, where he has inserted double the power of the undershot wheel (or very near it) according to his own experiments. low.

The horizontal wheel may be used in any fall however high or

$$
\text { In low Falls. }
$$

Example.-Let the depth of the fall be two feet, diameter of the wheel twenty feet, number of cuts twenty-four, and their depth four inches;

Then, by the 'Table, the angle between two cuts is $15^{\circ}$, and its versed sine $\cdot 034074$; therefore,

$.034074 \times 10 \times 24 \times \frac{1}{3}=2.72592$ square feet, or the area of a rectangular passage equal to that of the perpendicular sections of all the cuts.

This may therefore be considered as the base of a column of water, the height of which is the perpendicular distance from the surface to the centre of pressure or the middle point of the cut, which in this case is 22 inches, or $\frac{1}{6}$ feet; hence we have

$2.7592 \times \frac{1}{a}=5$ cubic feet, nearly $=5 \times 62.5=312.5$ pounds weight constantly impelling the water through the euts against the floats quite round the wheel, and $312 \cdot 5$ divided by 24 , gives 13 pounds for each cut or passage. The greatest velocity of the wheel will be $6 \sqrt{ } \overrightarrow{I I}=\sqrt{66}=8 \cdot 124$, or about eight feet per second; and therefore when it works to the greatest advantage will be four feet per second. Then

as $4: 1^{\prime}:: 20 \times 3 \cdot 1416: 15^{\prime} \cdot 7$ time of a revolution.

$$
\text { In high Falls. }
$$

In order to obtain the full force of the water here in the same R 4 manner 
manner as in low falls, the hright of the walls of the reservoir would require to be equal to that of the fall. But,

This however is not neccsary, as both the reselvoir and inner cylinder may be covered at any proper hejght, as denoted by the dotted line in the plate, but the reservoir must be made watertight.

A pipe may then be brought from the surface of the water to the bottom of the reservoir, where it must be so fixed that the water may flow from it in the same direction as the wheel tums, which, in that respect, will augment the power.

But as this supplying pipe will be in the place of a reservoir of water, the area of a section of it ought to be greater than the sum of the areas of the perpendicular sections of all the cuts, and it ought also to be constantly full up to the top, otherwise the water would not be supplied so fast as it could pass through the cuts, and a part of the power would be lost, unless there were a contrivance for covering or shutting up part of the cuts.

Exrmple.-Let the depth of the fall be 81 feet, diameter of the wheel 10 feet, number of cuts 30 , and their depth half a foot.

Then, by the Table, the angle between two cuts will be $12^{\circ}$, and its versed sine .021852 ; therefore,

$.021852 \times 5 \times 30 \times \frac{1}{2}=1.6389$ square feet, which is the area of a rectangular passage, equal to that of the perpendicular sections of all the cuts, and the diameter of a circular pipe of equal area will be $17 \cdot 3$ inches, therefore the diameter of the supplying pipe must be greater than this.

If the radius of the wheel and depth of the cuts remain the same, the greater the number is, the less will the area of the whole of their perpendicular sections be, and consequently, the less water will pass through them, but it will act nearer to the circumference; and therefore, in proportion to its quantity, will produce a greater effect.

Example.-Let the numbers be 12, 16, 30, 50, then these multiplied by their respective versed sines will be

$12 \times \cdot 133975=1 \cdot 6077$

$16 \times \cdot 076120=1 \cdot 21792$

$30 \times \cdot 021852=0.65556$

$50 \times \cdot 007885=0 \cdot 39425$ )

which are the ratios of the sums of the areas of their perpendicular sections.

Hence, when the quantity, or supply of water is great, the number of cuts must be small, and, on the contrary, when it is small, the number of cuts must be great in order to obtain the greatest effect. 


\section{The follouing Problems may sometimes be useful :}

Pros. 1. Given the angle between two cuts, to find the number of cuts.

Rule. Find the angle in the table, and against it stands the number.

Рroв. 2. Given the number of cuts, to find the angle between two.

Rule. Find the number in the table, and against it stands the angle.

Prob. 3. Given the angle between two cuts and the radius of the wheel, to find the width of a cut.

Rule. Multiply the versed sine of the angle by the radius, and the product is the width of a cut.

Р ков. 4. Given the number of cuts and the radius of the wheel, to find the width of a cut.

Rule. Find the versed sine (against the number) in the table, and multiply it by the radius for the width.

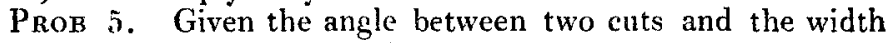
of one, to find the radius of the wheel.

Rule. Divide the width of the cut by the versed sine of the angle, and the quotient is the radius.

Prob. 6. Given the number of cuts and the width of one, to find the radius of the wheel.

Rule. Find the versed sine (against the number) in the table, by which divide the width, and the quotient is the radius.

Prob. 7. Given (D) the depth of the fall, and $(d)$ the diameter of the wheel, both in feet, or both in inches, to find the number of revolutions in a given time.

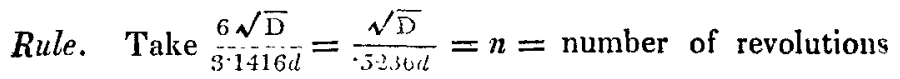
in a second; then $n \times$ number of seconds in the given time gives the number of revolutions in that time.

Example. Let $\mathrm{D}=45$ feet and $d=5$ feet; then

$\sqrt{45} \div \cdot 5236 \times 5=2.562$ revolutions in a second $=n$, and $2 \cdot 562 \times 60=153.72$ revolutions in a minute.

ProB. 8. Given (D) the depth of the fall, and $(n)$ the number of revolutions in a given time, to find the diameter of the wheel.

Rule. Find $(n)$ the number of revolutions in a second:

Then since $\frac{\sqrt{\mathrm{D}}}{.5236 \mathrm{~d}}=n, . \therefore \frac{\sqrt{\mathrm{D}}}{5236 n}=d$.

Example. Let $\mathrm{D}=30$ feet, and the number of revolution. 
in a minute $=138$, then $138 \div 60=2 \cdot 3=n$, and

$\sqrt{30} \div \cdot 5236 \times 2 \cdot 3=4.55$ feet, the diameter required.

It may be proper here to observe, that when the quantity of water is not too great, nor the fall too high nor too low for the overshot wheel ; its power will exceed that of the horizuntal; yet, in general practice the horizontal will certainly be superior, for the following reasons:

1. Because the horizontal will act in any fall, its friction will not inerease by the increase of water, and as it receives the water quite round the circumference, it will (when the supply is sufficient) work with a quantity greater than can be applied to the overshot without great loss of power.

2. In the horizontal, while the depth from the surface of the water to the centre of force in the cuts remains the same, the power will increase with the guantity of water acting against the floats, or as the depth of the cuts; and since the quantity of water increases also with the circumference, or the radius of the wheel: Therefore

The power will be as the product of the radius and depth of the cuts.

Thus, if the depth of the cuts be made three times as great, and the radius twice as great, the power will be $3 \times 2=6$ times as great. Hence

If, in the model, the depth of the cuts be made 10 inches, and the radius 60 inches, or ten times as great, the power will be $10 \times 10=100$ times as great, though the depth of the fall would be increased only $4 \frac{1}{2}$ inches.

3. When the depth of the fat is given, the size of the overshot, as also its velocity, is fixed ; for if its diameter be 16 feet, its velocity, to produce the greatest effect must be five feet per second; but the velocity of the horizontal wheel, with a fall of 16 feet, must be 12 feet per second. Again, an overshot of 36 feet diameter must move $5 \cdot 33$ feet per second; but a horizontal with a fall of 36 feet must move with a velocity of 18 feet per second, to produce the greatest effect.

4. The overshot must have a wheel fixed on its axis, and connected with other wheels or machinery before any effect can be produced; but in the horizontal this is sometimes not necessary as a mill-stone may be fixed on the top of the axis, and made to revolve with a proper velocity, without any connexion with other wheels. 
TABLE showing the Angle between two Cuts with its nalunal versed Sine from 9 to 52.

\begin{tabular}{|c|c|c|c|c|c|}
\hline & Angle. & V. Sine. & & Angle. & V. Sine. \\
\hline 9 & $40 \quad 0$ & $\cdot 233956$ & $3 \mathrm{l}$ & 1136.79 & $\cdot 020470$ \\
\hline 10 & 360 & $\cdot 190983$ & 32 & $1115^{\circ}$ & .019215 \\
\hline 11 & $3243 \cdot 63$ & $\cdot 158746$ & 33 & $1054 \cdot 55$ & .018071 \\
\hline 12 & $30 \quad 0$ & $\cdot 13: 975$ & 34 & $10 \quad 35 \cdot 29$ & $\cdot(1) 7027$ \\
\hline 13 & $2741 \cdot 54$ & $\cdot 114544$ & 35 & $10 \quad 17 \cdot 14$ & .016070 \\
\hline 14 & $2542 \cdot 86$ & .099031 & 36 & 100 & .015192 \\
\hline 15 & $24 \quad 0$ & $\cdot 086454$ & 37 & $943 \cdot 78$ & .014384 \\
\hline 16 & 2230 & .076120 & 38 & $928 \cdot 42$ & $\cdot 013639$ \\
\hline 17 & $21 \quad 10 \cdot 59$ & .067528 & 39 & $\begin{array}{lll}9 & 13 & 85\end{array}$ & .012950 \\
\hline 18 & $20 \quad 0$ & $\cdot 060307$ & 40 & 9 & .012312 \\
\hline 19 & $1856 \cdot 31$ & .054183 & 41 & $846 \cdot 83$ & $\cdot 011720$ \\
\hline 20 & 180 & $\cdot 048943$ & 42 & $834 \cdot 28$ & .011169 \\
\hline 21 & $17 \quad 8.57$ & $\cdot 044427$ & 43 & $822 \cdot 33$ & .010657 \\
\hline 22 & $1621 \cdot 82$ & $\cdot 040507$ & 44 & $\begin{array}{ll}8 & 10 \cdot 91\end{array}$ & .010179 \\
\hline 23 & $15 \quad 39 \cdot 09$ & .037083 & 45 & $8 \quad 0$ & .009732 \\
\hline 24 & 150 & $\cdot 034074$ & $46^{\circ}$ & 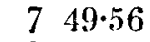 & .000314 \\
\hline 25 & $1424^{\circ}$ & .031417 & 47 & 734.57 & .008923 \\
\hline 26 & $1350 \cdot 77$ & $\cdot 029058$ & $4 \mathrm{~S}$ & 730 & .008555 \\
\hline 27 & $1320^{\circ}$ & •026955 & 49 & $720 \cdot 82$ & .008210 \\
\hline 28 & $1251 \cdot 43$ & $\cdot 025072$ & 50 & 712 & .007885 \\
\hline 29 & $1224 \cdot 83$ & $\cdot 02,3379$ & 51 & $7 \quad 3 \cdot 53$ & .007580 \\
\hline 30 & $12 \quad 0$ & .021852 & 52 & $655 \cdot 39$ & $\mid \cdot 007291$ \\
\hline
\end{tabular}

II. Adanson, Ehury-street, Fivc-fields, Chelsea, August 20, 1817.

XLIV, On Elbing and Flowing Springs; with Geological Remarks and Queris. by A Connesposinest.

\section{To Mr. Tilloch.}

Srr, $-I_{\mathrm{N}}$ the Number of your Magazine for August, Mr. Inglis seems to have satisfactorily accounted for the ebbing and flowing spring of fresh water at Bridlington quay, by the pressure of the sea upon a stratum of flexible clay which divides the fresh from the sea water.

His assertion that this bed of clay extends to the Spurn Point is probably correct; bit he is not so, in supposing that it will be found to rise and fall with the ebbing and flowing of every tide ; at leist that effect is not produced in the neighboushood of Ilull, 